\title{
Can Technology be a Solution to Operational Impediments? The Story of EZ School at NVJR College of Engineering:
}

\section{A Case Study}

\section{Vinay Chaganti*}

\section{Background}

"We see that you have the right skills to manage our processes and bring them to a better shape. We hope you can bring out an operations manual in about one year, so that all the administrative processes will be streamlined", said Lakshmipati, Principal, NVJR College of Engineering (here after referred to as NVJR), to Bharat, Assistant Professor, Department of Management. Bharat thanked the Principal for giving him the opportunity to make a contribution to the operations in the college.

This is June, 2012. Bharat joined the college ten months before this meeting took place. He became a teacher by choice and had a strong inclination towards research. Part of the reason why he joined NVJR, leaving an option to stay with a deemed university, was the promise of the institution in supporting research and related academic activities. But in the short stint of six months, he finds that the administrative processes are a serious drag to the academic activities. There were difficulties for the faculty in corresponding with the finance department to get the advances and reimbursements necessary for attending conferences and workshops. There were communication delays in approving leave requests that caused concern. There were long meetings with neither decisions nor action plans. These and a few more glitches meant that administration in the college is rather inefficient.

Assistant Professor, School of Management Studies, MVGRCE, Chintalavalasa, Vizianagaram, 535 005, Email: vkchaganti@mvgrce.edu.in 
Having worked in documentation intensive settings, with IT firms as a techno-functional analyst, and having exposure to consulting practices, Bharat felt that he should propose to offer his services to the college, to study and offer suggestions to improve administrative processes wherever possible. With that intent, he compiled his observations, his previous work related documentation, his updated resume, and a proposal of what he is willing to offer to the college, and met the Principal. After two weeks of sustained effort in waiting and trying to meet the Principal, in this meeting, Bharat had the Principal acknowledge his observations, agree to his proposal, and express that he will be happy to support Bharat.

In the next two weeks, Bharat found himself in meetings that he wouldn't generally be invited to. In the meetings all working committees in the college, Principal ordered his assistant to keep Bharat invited. Principal told Bharat that the idea behind asking him to take part in all meetings is to give him more exposure to the status quo. Bharat too felt that this was a good opportunity to learn how different people in NVJR discuss and do what they do. While attending these meetings, Bharat learnt that there were issues across all operations of the college; however, few of them manage to scrape through to meet their basic objectives.

One of the strongest barriers for improving processes, as Bharat found, was to get these committees and people to set time bound goals and then adhere to these set timelines. Lack of clarity in roles and responsibilities, and a significant overlap between what these committees do, was also becoming another challenge to overcome. Documentation did not exist for operations; and recording responsibilities or reporting progress was also a significant challenge. On an occasional meeting with the Principal, Bharat presented these observations softly, and sought more inputs. Principal admitted that there were efforts made earlier to try and document the roles and responsibilities of each committee, but those did not materialize due to competency gaps among the group of convenors. The kind of reception he was getting from the Principal, Bharat was sure that Principal was willing to improve the operations. Subsequently, the Principal brought in a template Bharat suggested to record the minutes of all meetings wherein the 
responsibilities and timelines are clearly recorded and tracked. Bharat was assigned the responsibility of assisting various committees in documenting minutes, and also maintain a copy of minutes of all meetings only to learn in process who does whatwhich could have subsequently helped in clarifying and documenting roles and responsibilities.

Bharat was in search of a more suitable point to improve the operations. In one of the meetings of the academic council, Principal mentioned that it has remained a challenge for the college to set up the employee service registers. To Bharat, this seemed to be a reasonable end to begin with, at least for the gamut of personnel related operations. Information that comes through this service registers could become the pivot around which other operations such as leave management, conference and workshop attendance, research projects could be aligned suitably to fit into a framework where reporting the information and progress of any employee in the college should be fairly easy-which was not the case in status quo.

So, seizing the occasion, Bharat proposed that there could be a template to record all details necessary for maintaining personnel files, and that details can be obtained from employees themselves by having them fill in the template. It was later realized that some details needed to come from the central administrative office such as pay scales, increment dates, loans and advances, and other finance related information that individual employees may not necessarily keep track of. Accordingly, a template was made, with different components to be filled in by the individual employee and the central administration office, and soon a circular was sent around communicating the intent behind seeking information. Thinking it was reasonable, Principal had given the employees a month time to send back the filled in template to Bharat, who would then organize all information appropriately and make it ready for further use.

After several reminders from Bharat to Principal that this activity needs follow up, and after several reminders from Principal to the departments-requesting their employees to send the filled in template; of the ten departments in the college, only one responded with a week delay. Others did not respond even after two weeks 
from scheduled close date. After several trials to meet Principal and escalate the issue, Bharat could one day pass the message that personnel information is not obtained in time, and that other improvement plans were getting delayed as a consequence.

Knowing that timeliness is a challenge, Bharat started seeking alternative ways of getting information. There were two sources he could identify. First was the Vice-Principal's office where all employees, like Bharat, would have submitted their joining report. With joining report was taken lot of other information that could have become a part of the personnel file if there were one. Second was the library where all employees would have taken their employee ID card. Since library issues ID cards, it was only logical that they should have maintained a database of all employees in the college.

Ranga Sai, Personal Assistant to Vice-Principal, was co-operative, and shared all information he could with Bharat. What surprised Bharat was that the Ranga Sai never maintained the field 'employee ID' in any of his data sheets which otherwise are reasonably clever and complete. Mahesh Yadav, Librarian, was directed by the Principal to assist Bharat, and he too shared the employee database that was with them. Interestingly, the library had two versions of data: one was generated from software that they use for recording all users and all users' transactions, SOUL, and the second was a database that they had maintained using MS-Access which recorded 'employee ID' field. As a process, every new employee would go to the library and apply for an ID card, and the library enters his details in these two separate databases through two separate systems. Data supplied by library had inconsistencies because ID number was manually fed into these two databases opening up a scope of committing an error, which did happen on few occasions. Also, the data had redundancy - the ID number would change for employees if they get promoted or transferred between departments, and the library maintained all the ID numbers that an employee had since joining to his current dayonly not being able to find out which would be the latest. Bharat carefully studied all versions of data available, and figured out that he should get Ranga Sai and Mahesh to coordinate with each other, 
clean up the data, and come out with a version that is more reliable and usable.

At this point was also a question as to who should be held accountable for the correctness of the data and who should be taking the responsibility for inputting data from other processes that would subsequently be pumping in information into this databank. Seeking suggestions and input, Bharat met Rao, Assistant Principal. Rao was actively involved in making up reports for AICTE, other accreditation and funding agencies. He listened patiently to Bharat on the efforts going on, and acknowledged that it was indeed necessary that someone took a deeper look into how efficient the operations were.

Before answering the question, the Assistant Principal had another suggestion to offer. He informed Bharat that the college had long had the intent of streamlining the operations, and had actually obtained EZ School, software to facilitate better workflow. He also mentioned that the responsibility of deploying and managing the software has changed hands with little success everywhere. He opined that this software, if it can be deployed properly, can answer most of the operational impediments. Given the technofunctional background Bharat carried, he was willing to try this technology solution. Technology that can record information and can intelligently produce reports was seen as an ideal solution by many, Bharat not being an exception. At this point Ram, VicePrincipal, pitched into the conversation between Bharat and Assistant Principal, and promised his support to Bharat in this effort-reviving EZ School.

\section{The EZ School Story}

“EZ School works very well for two colleges I know. So far we were unable to figure out why it does not work for us. One reason we believe that led to its failure we feel there were several other issues with its implementation, because lot of effort went into it with very little outcome. Right now, Raju from Department of M.C.A. has control of the software. He would be working under the guidance of Srinivas, Head, Department of M.C.A. You could contact them to know more about the software, how it works, and 
why it is not working now. Don't hesitate to drop a word in case you need our support. We will be glad if you can do something about it", Bharat recalled the words of Assistant Principal. Bharat wanted to explore into the details of the software and what it does, the organization that sold the software to NVJR, the terms of contract that the parties share, and the support that the vendor pledged to provide.

Srinivas being unavailable, Bharat approached Raju and sought assistance in learning more about EZ School. But Raju considered it strictly necessary that he be directed by Srinivas to speak any detail to Bharat. Accordingly, Bharat waited for Srinivas and approached him. The only piece of information Bharat could get from Srinivas was that he was earlier working in the Department of C.S.E., and was also the convenor of eServices Committee; a committee that took care of software and hardware maintenance in the college. As a part of his role in eServices, he was given the responsibility of maintaining EZ School. But his tenure on eServices was between February, 2008 and January, 2011, after which he handed over the responsibility and all documentation - of which one file belonged to EZ School - to Kalyan from the Department of C. S. E. Srinivas ended the conversation suggesting Raju that only on the direct instruction from the Assistant Principal may he support Bharat and give him necessary assistance.

Bharat and Raju went to the Assistant Principal. Not only did Raju get the instruction that he should assist Bharat, but he also had troubled time facing a series of questions about why the software was not functioning as it should, and what he was doing about it. His only defence to any question that flew at him was that the software license was not renewed. At this time again, the VicePrincipal voiced his devil's advocacy reminding Raju that the software may not have been renewed, but that it was not functioning even when it was appropriately paid for. Visibly, Raju could not shield this argument and put the responsibility on Srinivas.

On their return to the Department of M.C.A. where the server system that runs EZ School was maintained under the supervision of Raju, Raju shared few things with Bharat. In a reasonably lengthy discussion, Bharat noted the following points: 
1. The software was bought by the college without asking anybody whether it works.

2. Then there was a committee (EZ School committee) formed to ensure that the software was put to use, of which Raju represented his department.

3. An individual by the name Kiran represented the organization that sold EZ School to NVJR, and had installed the software and trained the Junior Assistants of all departments to input data into the system. Subsequently, he trained the EZ School committee members also on using the system.

4. The software was bought in 2008, and was renewed for three years. The renewal payment for 2012 was not made since the software was not working.

5. Kiran was called several times to assist in using the software, even after Kiran left the organization that sold EZ School, because he was living close to the college. He was paid on a per day basis, and the payment was made only after the Junior Assistants reported that they were satisfied with the training and assistance he provided.

6. Now, there are problems running the software, but Kiran cannot be called because he moved to a different city, and also he had problems getting paid the last time he provided his services to the college.

7. Even after Srinivas left eServices, he still manages EZ School only because he told Principal that he would get the students to work on the software and put it to use.

Raju tipped off that conversation saying that EZ School was a total mess, and that he never really understood how to use it. After reaching the department, it took him some time, but Raju finally obtained the Administrator ID and Password to login to EZ School. It was the first time Bharat had a look at the software that senior faculty in the college have so recommended. Even as he laid his hands on the keyboard to operate the software and see what it has to offer, he still recalled his conversation with Raju that left more questions than answers. Some of them were: 
1. Why was the software renewed for three years if it was not working at all?

2. Why was EZ School responsibility separated from eServices?

3. When he still manages the software, how and why did Srinivas give the file to Kalyan?

4. When there are several competent faculty members, why did Srinivas have to say that students could work on the software and bring it into use?

5. If the software was renewed and the vendor provided his support, why did the college have to call on Kiran for assistance? Why not someone from the vendor organization?

6. Even while Kiran was relied upon; if he was paid only a satisfactory comment from Junior Assistants, why and what sort of problem did he have with his last payment?

7. What was the role of EZ School committee members who were also trained to use the software and what they did when there were problems with it?

Bharat logged into EZ School for the first time. The logon screen gave credits of the software to Colksoft Technologies Limited (CTL), Hyderabad. There was a hyperlink that lead to CTL's website. Curiously, Bharat clicked on the link to learn more about what exactly CTL had to say about EZ School. The website indicated that CTL offered technology solutions in many different fields, of which EZ School was an ERP Solution exclusively designed for educational institutions. It also indicated that EZ School was running successfully in more than 450 institutions in Andhra Pradesh alone, and had put up a list of all institutions that are using the software. Bharat found on the list, the name of NVJR too. The names of two colleges that Assistant Principal earlier mentioned were also listed, and there were several others in the close vicinity that Bharat could immediately relate to. It took Bharat by a little surprise that the software so widely used in the neighbouring colleges just doesn't work at NVJR, or so is the claim, Bharat thought and moved to browse more information. There was 
a document on CTL's website that explicitly listed the capabilities of EZ School in pin point detail. The same document indicated that the software can be bought in three different packages each of which unlocks different and more modules and utilities in the software. He recorded the contact details of CTL from their website.

Bharat was anxious to explore the software's potential. Closing the website and figuring out the basic options in the software almost happened simultaneously. The first tab in the software was to help the institution come up with a set of time-tables for all departments, all classes of each department, and all sections of each class. It is a complicated task to perform manually, considering the range of courses, nature of subjects, number of faculty, and their teaching hour preferences. Software that could record all these constraints and throw up time-tables would mean lot of time and energy saved for the academic coordinators. Browsing through the options, Bharat found that there were problems in this module. Firstly, the software did not fully automate the time-table construction, but it was still partly manual. Also, it did not really offer to filter the resources (faculty members) by any criteria, such as department, so that time-table could be easily built; but all the faculty members of the college would be listed on one screen for each hour allocation to be made in the time-table. These two issues made the time-table module, hard to understand, and difficult to use. Especially, given that the college works on a committee based structure and that each department has an academic coordinator who would draft the time-table; it was not pragmatic to imagine that all the academic coordinators could work together and input all necessary constraints into the system, even if the software were to be useful. These were sufficient to Bharat to indicate that at least this module in the software was difficult to bring into use. Also, with his past experience as frame of reference, Bharat felt that EZ School was hard-coded and closed-ended as a system, and that it was not user-friendly.

With a hope that software updates, if any, could have enhanced the system and its work flow principles, Bharat recorded the software version (EZ School, Ver. 3.80) and wrote an email to the support contact that he found on the CTL website. 
Reviving the software was the objective when Bharat took the suggestion from Assistant Principal. That meant Bharat had to work smartly to understand the entire story of EZ School. Trying to answer some of the questions that he got after his discussion with Raju, he met Srinivas to find out how and why he gave the EZ School file to Kalyan while he was managing the software, and why was EZ School separated from eServices. Srinivas mentioned that he had ideas of having the students from his department to work on the software, so that there can be work productive to college, and that the work would also satisfy that academic project criteria for students. Following the idea, EZ School system which was sent to Kalyan in Department of C.S.E, came back to Srinivas in Department of M.C.A. However, about the file, Srinivas reasserted to Bharat that all the documentation was handed over to Kalyan in January, 2011. There was no mention as to why the file was not brought back when the software was brought back from eServices.

Bharat met Kalyan to source the file pertaining to EZ School. Bharat brought Kalyan into the context in which he was trying to get the file, and requested necessary support. Kalyan mentioned that he took over the eServices responsibility in February, 2011, and that he is ably supported by Prasad, System Administrator, and his team of technical assistants. Kalyan recalls sending the file also when he sent back the system to Srinivas. But to be confirmed about what he says, with his team and with Bharat, he verified all the files that he took over from Srinivas and all the files that he maintained too. EZ School file was not found, but Kalyan clarifies a couple of things to Bharat.

1. Nothing has been paid for EZ School in 2011.

2. Software was bought by the college without asking anybody whether it works.

One of the points affirmed what Raju shared with Bharat earlier. But the other point about not paying anything for EZ School contradicts what Raju said-that the software was renewed till 2011, and it does not work only because it was not renewed after that. Bharat seeks more input from Kalyan, but Kalyan directs Bharat to Prasad. 
Prasad indicates to Bharat that the college ignored paying the Annual Maintenance Contract (AMC) of INR 35000. He confirms that Kiran was called in by the college for assistance, but posed problems in making his last payment. Yet, at this point in the conversation, Prasad indicates to Bharat, that Kiran may make himself available to college if only he got a word from Srinivas. He adds that Kiran was paid and treated well by the college for a long time, but that Kiran was not open to teaching how the software works, how the software can be best used-not even to the technical assistant who held the administrator rights when the software was first used. Ending the conversation, Prasad referred Bharat to Satish, Technical Assistant, Department of C.S.E., who held the administrator rights to the software.

Satish looked pessimistic and dissident, when Bharat mentioned that the objective was to try and see if they could together revive the software and put it to good use. To Bharat, it appeared as if Satish had a limit on the number of words he would use about EZ School. Only two things that Satish had to share were:

1. Satish was working under the guidance of Srinivas when the software was bought, and that he only generated reports when other departments requested.

2. The only other thing that he did on the software apart from generating reports, was to correct data if the input was made wrongly. Here, Satish indicated that there were a number of tables in the backend that were to be checked and corrected for every data entry mistake someone committed, and that it was a long procedure.

Bharat referred to the notes he made. He had that critical question to answer before he could make any further strides with regard to EZ School-the nature of contract between NVJR and CTL. Raju mentioned that the software was not renewed which is indicative of a licensing model, and Prasad mentioned that the AMC was not paid for which is indicative of a one-time payment for the software, and several payments for the post-sale support if the college opted for it. Under a licensing model, the support provided by CTL should have been extensive because client relation matters more. Under the one-time sale model, the support services of CTL would 
form a different agreement, and the terms of that document had to be understood. In either case, knowing the nature of contract was essential to learn what kind of support CTL might be called on to provide to NVJR. Bharat was still eagerly waiting for CTL's response to his email.

Not willing to get back to Srinivas at this point, Bharat went to Sanyasi, Finance Officer, to see if he had any copies of the contract between NVJR and CTL. Any payment from the college should be duly approved by the Finance Officer, and Bharat was hopeful of finding a copy of that contract here. Sanyasi too mentioned that he took over his responsibility only in 2009, which is well after the software was bought, and that he does not have the documents Bharat was asking for. Subba Rao of the Accounts section was working with NVJR for thirty years, but he mentioned to Bharat that there may only be a bill pertaining to EZ School that he can supply, but that too if Bharat was clear when exactly the software was bought, the year and the month. File was not sourced at either of these points in the finance department, but again, Sanyasi and Subba Rao had that same point to share-software was bought, but it does not work. They added that they are unwilling to use the software unless it is rigorously tested, and their assistants are fully trained to input data and generate reports like they want.

Another idea that struck Bharat was to see if he could find any more useful information from the senior faculty members who were a part of eServices or EZ School committee between 2008 and 2010. From his past meetings, Bharat began to believe that faculty members from IT department are well prepared for meetings, and that they are more organized than other departments. With a hope that someone might be able to help, Bharat walked into the IT Department. Also, Bharat had high regard for Sitaram, Head, Department of IT, who had for long worked in the industry. Sitaram was very clear in what he thinks and what he does, which perhaps permeated through to the faculty, glimpses of which they show in other committee meetings. Sitaram was not available, but Nagesh responded to Bharat. Bharat silently recorded the notes:

1. Nagesh was a member of eServices when EZ School was bought, but later he transferred the responsibility to Reddy from his department. 
2. When EZ School was bought, Nagesh and other faculty from IT department tested it and have reported to the senior officials that the software was hard-coded, closed-ended, and that it is preferable to have a technology that is more open-ended than EZ School. He went on to add that their recommendation was not to renew EZ School, but look for alternatives.

3. IT department continued their stand on EZ School, even after they patiently implemented the software for a full semester. Their specific observations were:

a) Software does not allow a sixth parallel user to login to the system, and hangs without response if someone does.

b) There was facility to input data from the front end, but there was none to edit the data for correcting wrong entries; for which they had to contact the administrator - in this case, Satish.

c) Students' data would be input once should have been sufficient ideally, but the system would not automatically promote the students at the end of the semester into the next, but that had to be done manually from the backend; again for which Kiran was to be called.

Bharat tried to meet Reddy, but since Reddy was unavailable, he came back to working on the software himself. This is the second time Bharat logged into EZ School. But before Raju allowed Bharat to do that, Raju established a register in which Bharat had to record the date and time he began using the software and the time at which he logged out. For software that lay dead and unused for more than six months, Bharat thought it was an unnecessary exercise, but Raju had his concerns. The new formality was finished, and Bharat proceeded to explore the software again.

Bharat searched eagerly to find the master log that records what users have been doing on the system. It was found, and Bharat started making notes of which module was used most and which module was used least. Grabbing his attention was the number of 
times payroll was generated using EZ School. For four consecutive months in 2011, July to October, payroll was generated using the software after which there is nothing on the log. Apart from the payroll, the usage of other modules was ignorable.

At this time, Bharat also wanted to take a look at the help document and see what might be available. To his surprise, the help function did not work in EZ School, but the help document was put on the desktop as a separate file. Having worked on technologies before, Bharat knew that was not how help files are supposed to be available. However, he still continued opening and reading the help document, and after a few minutes he wrote down one word, 'useless', and closed the system for the second time with discontent.

By this time, it was clear to Bharat that trying to implement all modules in EZ School might land the entire exercise in a soup. The best way he thought it could proceed was to try and bring in one module into use at a time. And payroll probably was the module to be revived first given the usage history it had. So, Bharat moved to Central Administration Office to find out who was using it.

Bharat found that Ranga Sai was the one generating payrolls. In his previous interactions, Bharat knew that Ranga Sai was very organized and efficient in the way he works. Also, Ranga Sai was open to share and learn, and always sought better ways of doing his job whenever he interacted with Bharat. Bharat took his opportunities with Ranga Sai to learn what was going on with the operations of NVJR. So, to find that Ranga Sai stopped using software that could have made his job easy had taken Bharat by surprise. Bharat's question to Ranga Sai was on a subtler tone, as to why was the software not used after October, 2011. Ranga Sai had a simple answer and a few suggestions to Bharat:

1. Payroll management is a process that has many fields which are calculated on the basis of one value, the basic pay. However, while the formulae are same, the percentages of benefits given to different employees are different. While in an excel sheet these values are easily computed, in EZ School, the same data had to be entered manually. And if one mistake was committed, it would again lead to a long 
follow up procedure, not in rectifying the mistake in the system, but in answering seniors as to where exactly the mistake was committed and requesting new bills for additional payments or receipts for deductions whichever is the case. It was hard to use it for four months, but we tried it only because generating salary certificates for employees was easy. Since, Ranga Sai figured a way of generating salary certificates using excel macros, he thought EZ School can be dispensed-and now, he finds the process more auditable.

2. Against the claim that Assistant Principal made that the software works well in two colleges, and against what the CTL's website had to say that over 450 institutions successfully use EZ School, Ranga Sai says that these colleges have already shunned EZ School, and have taken to alternative technologies such as SAP. He shows the old pay slips of few employees who have left those colleges to join NVJR as a proof, and Bharat had to acknowledge that Ranga Sai's claim was supported by evidence.

3. Ranga Sai adds that whoever has taken the responsibility of managing EZ School had to face only hard consequences, because he thinks that there are fundamental problems with the way software is built. Ranga Sai's frame of reference was his experience of having worked with different technologies prior to joining NVJR.

After this conversation with Ranga Sai, Bharat could figure out that there was serious resistance to change even if he were to bring up EZ School again. Everyone he met so far was against the use of this software, and there were just too many issues reported. Moreover, the nature of contract that NVJR and CTL shared was still to be discovered. Bharat rephrased his objective: it was not to revive EZ School anymore, but it was to find out whether people are willing to use it if the problems they pointed out were solved. The revised objective became critical to either meeting or chucking the original objective. Bharat decided to meet the Junior Assistants who were trained to use the software and learn from what they had to say. 
Logical beginning for Bharat was to meet Neeraja, Junior Assistant, Department of M.B.A, department where Bharat works. Trying to explore how Neeraja felt using the software, Bharat found out that the software was used only to input attendance and nothing more. Talking about why she did not use the software, she mentioned that she was unable to split the students into different groups on the basis of their specializations which meant that the attendance module was not usable anymore. Bharat went back to checking the software himself to validate what Neeraja said, and figured out that there was an option to split students on the basis of specialization, but that option was active only for the administrator. So Neeraja was not wrong when she said, she could not split, but the bigger problem was that she did not know what the software could do. Bharat found that this must have been a problem with other departments too, and met Rajesh, Junior Assistant, Department of IT, who informed that he was aware of the option and that he routed such requests to the administrator, Satish. Another problem unearthed here, that the understanding of the software and its potential, among different junior assistants was also inconsistent. What junior assistants had in common to share with Bharat was that they were satisfied with Kiran and what he had to offer, because Kiran managed to solve problems they encountered. But they were disappointed with Kiran not being available when they wanted him in later periods.

Bharat went back to the Assistant Principal to report his developments and shared the entire story thus far. It was absolutely ridiculous not being able to trace the contract document between NVJR and CTL, Bharat thought. At this time, another senior colleague, Chandra shared a piece of information that filled in a big gap in the story. He mentioned that the software was purchased and paid for by Ram, the Vice-Principal. At the end of the day, Bharat found himself and everyone he met in the college silly, that they could not even guess who could have paid for the software. It would have only been better had Ram been able to find a copy of the document himself. But Bharat's request to find a copy of the document was postponed for the next day saying it would be there somewhere. Moreover, Ram mentioned that they could call anytime to CTL and get information that Bharat was trying to get. Bharat left the office with an air of discontent filling his heart - that 
he was so close to finding the origin of the story, but he still could not clearly find it. Just as the day ended, Bharat received a call from Hyderabad. It was Pratika on the other end, representing CTL. She received Bharat's email and wanted to discuss the matter in more detail. She was from the CTL's support division. Bharat had requested Pratika about the nature of contract that NVJR and CTL shared and asked if she could source a copy of the contract. Pratika requested for a day time and called Bharat the next morning.

The next morning, Pratika called Bharat and shared some information:

1. NVJR bought EZ School in January, 2008. Ram paid for it.

2. AMC costs INR 35000 plus $12.36 \%$ tax.

3. Hardware key costs INR 10000.

4. Updates will be given free of cost.

5. As part of $\mathrm{AMC}$, online and phone support is free; two days of training upfront may be offered to NVJR, conditional to NVJR paying the Travel and Dearness Allowance to CTL resources coming to train.

To Bharat, these things did not matter as much as the gaps he had to fill in the story. He pressed on Pratika that he cannot recommend his college to consider AMC unless he can get answers to the problems pointed out by so many employees within the college and unless he gets to test the latest version of the software. She responded to Bharat by bringing Arun, Tech. Support, CTL, into the line to answer Bharat's queries. Bharat shared all the issues that were reported by people he met earlier, and some of the issues that he himself found on the system. Arun's response was so brief and adamant; it reminded Bharat of Satish's response. All Arun had to say was:

1. It is a server issue. Your server does not meet the specifications we had given.

2. Providing updates does not mean the software can do wonders now, but the problems you point out do not exist in the system. 
3. Latest version cannot be given for trial, but a demo can be arranged if the college paid INR 5000 for it, which can be deducted from the AMC if the college opts to pay for it.

There was absolutely no conversation from CTL about the deployment plan for EZ School, not matter how much Bharat pushed for it. Just as Bharat thought that the conversation was going nowhere, he also found some answers to his earlier questions. He was now sure that the software was bought in a onetime sale by CTL after which NVJR had the option to pay for AMC. This meant that NVJR can also opt not to pay for AMC and still continue using the software in its current form, without asking for any updates. Even for that, Bharat thought, EZ School needs to be tested more professionally.

Ram called Bharat and told him that he discussed with CTL and that NVJRwas ready for paying the AMC, provided Bharat took on the responsibility of bringing EZ School into use. Bharat did not hesitate to air his views that the software needs to be tested more appropriately before deciding to pay for the $\mathrm{AMC}$, or thinking of redeploying the software.

Not willing to take chances in making technical comments on the software, Bharat thought it would be wise to consult Sitaram and ask for his assistance in testing the system and coming up with his recommendation. Without any delay, Bharat found himself sitting in a discussion with a very approachable Sitaram, who had much to share. Bharat only had to record:

1. EZ School is not entirely useless, but it also has serious flaws. It was bought based on one person's recommendation, and was sustained even against Sitaram's input that the software may not serve NVJR well.

2. Sitaram shove aside the server specification issue that Arun from CTL pointed out, mentioning that it is theoretically impossible to set a limit on the number of users logging into a system, but that CTL may not have done a 'system stress test' that might have indicated a practical limit. He cites an example of how faculty members in their department are all able to simultaneously log into one server that is of much 
lower specification than the one on which EZ School was installed.

3. Sitaram mentioned that he was unwilling to take up the system for testing, because of the history the system had, and opined that it was time to acknowledge that a mistake was committed in the case of EZ School and move forward with lessons learnt from it. Sitaram added that EZ School was not just an 'information system', but also a 'workflow system'; and that operations in NVJR did not align themselves to the workflow according to the rules embedded in EZ School, which he thought was the biggest reason for failure of its implementation. He also recalled that there never was a proper deployment plan in the case of EZ School. When Bharat reminded that there was a committee formed to take care of its deployment, Sitaram mentioned about the committee never having a charter, specific objectives, and documented responsibilities.

Bharat found wisdom in his conversation with Sitaram. He could finally find some indications of meeting his revised objective: are people willing to work on EZ School if it were to be revived. The answer was moving towards a glaring ' $\mathrm{No}^{\prime}$. There was still one more question that kept Bharat interested in EZ School: How does this software with so many issues and with minimal support from CTL, work in other institutions around? Bharat requested Assistant Principal that he be sent to at least one other college to learn how they use the software.

Assistant Principal brought the Principal into context about what Bharat was doing, and requested that Bharat may be sent to NXIS, another engineering college located at an hour's distance from NVJR. Principal spoke to Pradeep, Principal of NXIS, and arranged for Bharat to visit NXIS and assured that he would be assisted well for all information he might want to gather. Bharat thanked the Principal and began preparing for his visit.

\section{EZ School at NXIS}

By car, it took ninety minutes for Bharat to reach NXIS. It took five minutes of waiting before Bharat could meet the Pradeep. With 
whatever context he carried, Pradeep looked busy and ignorant of Bharat's presence. It took a long minute breath holding before Bharat got a welcome handshake from Pradeep. Pradeep knew the purpose of Bharat's visit. Soon Raghu joined the opening conversation between Bharat and Pradeep. Raghu was the administrator for EZ School at NXIS. With one closing sentence, "We use it, but it has bugs. We are the best pilot for CTL", Pradeep attached Bharat to Raghu for whatever Bharat wanted to learn.

Raghu and Bharat spent couple of hours together during which Bharat had lots of questions, Raghu had few answers and better friendly talk. In the course of the conversation, Bharat continued what he was at NXIS for-making notes. It read the following:

1. Software they were using was Ver. 3.83, an updated one compared to what Bharat worked on at NVJR, Ver. 3.80. Raghu indicated however that version does not matter as much. An updated version, in Raghu's observation, did not really mean it was better, but it only brought newer problems. While there was a more recent version available, this is one reason why Raghu opted not to update the software. One of the significant issues that a newer version brought was loss of data and few disabled functionalities.

2. Of the ten modules in the software, library, payroll, inventory, scholarships, and accounts modules were never used. Fee payments, attendance, exams, hostel, and time table modules were used; 'cautiously and only partially', Raghu indicated.

3. There was no limit on the number of users simultaneously logging into the system. In fact, NXIS had more than 300 institutional users, and access to reports from EZ School has been given to all students and parents. Unlike at NVJR, NXIS had given a web login facility to the system by configuring one of their servers appropriately. Their servers weren't too different in their specifications to what NVJR had.

4. Promoting students was not a problem, because NXIS had CTL develop an additional option called 'Semester transfer', 
wherein bulk promotions could be made by the administrator. This was not a default option.

5. While the problems mentioned at NVJR are all not serious problems, there were problems in the system that Raghu demonstrated.

a) There was an occasion when the change in university calendar, when incorporated in EZ School, messed up the 'transport fee' details in the system. When CTL was contacted, they pointed to the problem as 'unforeseen change in schedule', rather than providing a solution.

b) Student percentages are wrongly calculated giving meaningless values. There is very little understanding of how those wrong values are generated; but one guess is that the system might be including the marks of students from all their attempts, both success and failure, in which case there would be marks input many times into the system against the same subject that could be cumulated-resulting in wrong values.

c) There are options for generating reports of many kinds. But filters rarely work. Also, in case the institution seeks a report that is not already available in the system, it can only be obtained on a payment to CTL, which was unreasonable.

d) Time table module is only used to map teachers to courses. It does not really serve any purpose, except for record maintenance. One reason why time table does not point to conflicts in time table, Raghu thinks, is that the system does not distinguish between theory sessions and lab sessions - wherein lab sessions, two faculty would together attend the same session. This is probably one reason why conflicts are not pointed out.

1. In Raghu's opinion, the software was developed to assist schools with their administration. And the workflow in the 
system does not really fit the needs of an engineering college. He added that there an effort of eight months that a team within the college had put in, with a team from CTL, at the college premises, defining the requirements and customising the application. Even after that, Raghu recalled that there was a phase where the college wanted to dump EZ School, but continued using it.

2. Raghu had concerns with the support CTL provided. He thought that the support team were incompetent in responding to queries; rather they were good at throwing the blame on misuse of the system.

3. Raghu was cautious in his use of words when Bharat asked his recommendation whether NVJR should consider reviving EZ School. He reminded that it was brought in by a different set of people who were in authority, and that it may be inappropriate to spell out issues which they too would be aware of. He felt his job of working on EZ School was manageable.

Bharat, walking around the college and talking to others managing systems, found out that there are just five individuals managing a network of two thousand systems and website administration at NXIS, against the ten technical assistants for a network of thousand systems at NVJR. Unlike a quasi-bureaucratic administration at NVJR, Bharat observed a corporate style administration at NXIS. Just for a moment, Bharat recalled the committee based structure, and the big teams to work on singular issues, yet lagging in defining procedures and bringing out results. These observations did not make the notes, but were points for reflection. Bharat silently admired the principles of management he had studied as a student.

Before leaving NXIS, Bharat wanted to seek the suggestion of Pradeep, whether he would recommend NVJR to try and revive EZ School. In a five minute meeting, Pradeep said, "We brought the software to try and improve our administration. We have been using it for almost seven years. We are now in a position where coming out of it and trying new technology is not an easy option. I do not sell EZ School, it has issues; but if one wants a system, 
probably it is here". Bharat wanted to get a more specific response and prodded asking, "Would you use an open source technology if I told you it was better, or would you continue paying for EZ School?" The response was as diplomatic as it was the first time, "We need to explore our potential to adapt a new technology". One last question Bharat had to Pradeep was whether NXIS was satisfied with EZ School, and Pradeep's response was "For what we paid, I think we have to take what works". Bharat established the direction of the responses, thanked Pradeep and left NXIS.

\section{Bharat's Report to NVJR}

When Rao suggested Bharat to consider reviving EZ School, the objective was revival, because Bharat favoured Technology as a solution to solving operational issues. Through the course of his conversations with people at NVJR, he realized that technology alone cannot really offer a solution, unless there are people willing to let the technology work for them. That being the case with technology which offers a solution, in the case of EZ School, he wasn't even sure if he should persuade people to use technology, for there was no evidence that it offered solutions. So the objective was revised to figuring out if people would be interested in using EZ School if it was good. Bharat proceeded to test the system himself and found that some modules are usable, yet there wasn't any hint of willingness to use the system from stakeholders to making technology deployment fruitful. Interestingly, the root of the problem in the failure story of EZ School lies in not testing the technology whether it offers a solution before buying it, and then not having a proper deployment plan to bring it into implementation, whatever part of the technology was useful. Just to make a case that technology had its problems, the NXIS's experience could be added on to NVJR's woes with EZ School. While resistance to change is normal, now, the failure of EZ School also adds to that resistance individuals have in using even the decently working parts of technology.

Could NVJR overcome this and consider bringing parts of technology alive, so that it can answer at least a part of their operational issues? There are several other questions that NVJR needs to ask itself before bringing up that question, such as, is there 
a team that is willing to take up the initiative of deploying technology, owning the responsibility, ready to handle issues, and eager to make the technology work. If there is a team, then, is the team sufficiently competent to take on what they desire to do? Even if they were, how flexible and tolerant are current operations at NVJR to failure? Looking back at his notes, Bharat found tentative answers to all these questions. After a gasp, he thought to himself, there are better priorities to look forward to.

Bharat submitted his single line report to Rao, and it read:"It doesn't work always" 